\title{
Post-treatment Mac-2-Binding Protein is a Useful Predictor of Hepatocellular Carcinoma Development after Hepatitis C Virus Eradication
}

\section{Shunsuke Sato ( $\nabla$ syusato@juntendo.ac.jp )}

Juntendo University Shizuoka Hospital https://orcid.org/0000-0002-7480-7283

Hironori Tsuzura

Juntendo University Shizuoka Hospital

Yuji Kita

Juntendo University Shizuoka Hospital

Yuji lkeda

Juntendo University Shizuoka Hospital

Daishi Kabemura

Juntendo University Shizuoka Hospital

\section{Sho Sato}

Juntendo University Shizuoka Hospital

\section{Nozomi Amano}

Juntendo University Shizuoka Hospital

Noboru Yatagai

Juntendo University Shizuoka Hospital

Ayato Murata

Juntendo University Shizuoka Hospital

Yuji Shimada

Juntendo University Shizuoka Hospital

\section{Takuya Genda}

Juntendo University Shizuoka Hospital

\section{Research Article}

Keywords: WFA+-M2BP, hepatocellular carcinoma, hepatitis C virus, sustained virological response, interferon-based therapy; interferon-free therapy, direct-acting antiviral drug, liver fibrosis, risk factor, retrospective study.

Posted Date: March 11th, 2021

DOl: https://doi.org/10.21203/rs.3.rs-276843/v1 
License: (c) (i) This work is licensed under a Creative Commons Attribution 4.0 International License. Read Full License 


\section{Abstract}

Background and aims: Recent advances of direct-acting antiviral drugs for hepatitis C virus (HCV) have dramatically improved the sustained virologic response (SVR) rate, but hepatocellular carcinoma (HCC) development not rarely occurs even in patients who achieve an SVR. Wisteria floribunda agglutininpositive Mac-2-binding protein (WFA $-\mathrm{M} 2 \mathrm{BP}$ ) was recently developed as a noninvasive biomarker of liver fibrosis. However, the association between the WFA ${ }^{+}-M 2 B P$ level and HCC development after the achievement of an SVR is unclear.

Methods: We examined the association between WFA+-M2BP and HCC development in 552 HCV patients who achieved an SVR (Interferon [IFN]-based therapy, n=228; IFN-free therapy, n=294).

Results: Multivariate analysis revealed that a high WFA ${ }^{+}-M 2 B P$ level at SVR week 24 after treatment (SVR24) (hazard ratio $[H R]=1.215, P=0.020)$, low platelet counts $(H R=0.876, P=0.037)$ and old age $(H R=1.073, P=0.012)$ were independent risk factors for $H C C$ development regardless of the treatment regimen. Receiver operator characteristics curve analysis revealed that an WFA ${ }^{+}$M2BP level at SVR24 of $\geq 1.62$ cut off index (COI) was the cut-off value for the prediction of HCC development (adjusted HR = $12.565,95 \% \mathrm{Cl} 3.501-45.092, \mathrm{P}<0.001)$. The 3 - and 5-year cumulative incidences of HCC were $0.7 \%$ and $0.7 \%$ in patients with low WFA ${ }^{+}$-M2BP at SVR24 ( $\left.<1.62 \mathrm{COI}\right)$, and $4.8 \%$ and $12.4 \%$ in patients with high WFA $^{+}-\mathrm{M} 2 \mathrm{BP}(\geq 1.62 \mathrm{COI})$ were, respectively $(\mathrm{P}<0.001)$.

Conclusion: The assessment of liver fibrosis using the WFA ${ }^{+}-M 2 B P$ level at SVR24 is a useful predictor of HCC development after HCV eradication even in the IFN-free therapy era.

\section{Introduction}

Hepatitis $\mathrm{C}$ virus (HCV) infections represent an important global health problem leading to liver cirrhosis and hepatocellular carcinoma (HCC). At present, the World Health Organization estimates that 71 million people are chronically infected with HCV and approximately 400,000 people die every year from the complications of cirrhosis and HCC [1]. In Japan, it is estimated that 30,000 people died of HCC and $65 \%$ of all HCC deaths were due to chronic HCV infection [2].

Interferon (IFN)-based therapy, which was the standard treatment for chronic HCV infection until 2011, provided a sustained virologic response (SVR) in only $50 \%$ of the patients infected with HCV genotype 1 , which was dominant in Japan.

In addition, it was poorly tolerated due to adverse events, particularly in elderly patients or those with advanced stage disease. However, recent advances of IFN-free therapy with oral direct-acting antivirals (DAAs) dramatically improved the SVR rates and tolerability, and a large number of HCV patients currently achieved an SVR with this treatment. Previous studies have shown that the eradication of HCV not only reduces the incidence of HCC, but also improves all-cause mortality [3, 4]. However, HCC development is not rarely observed even in patients who achieved an SVR. Indeed, the annual incidence 
of HCC among patients who achieved an SVR with IFN-based therapy ranges from 0.4 to $2 \%$ [4-8]. Therefore, it is important to identify the risk factors for HCC development after HCV eradication.

Previously, we reported that the pretreatment Wisteria floribunda agglutinin-positive Mac-2-binding protein (WFA ${ }^{+}$-M2BP) level was a useful predictor of HCC development in patients who achieved an SVR with IFN-based therapy [9]. WFA+-M2BP was originally identified as a glycobiomarker of liver fibrosis, and the serum WFA ${ }^{+}-M 2 B P$ level is reportedly significantly associated with histologically confirmed liver fibrosis in patients with chronic liver disease [10]. At present, WFA ${ }^{+}-M 2 B P$ is generally used in Japan as one of the noninvasive biomarkers for the assessment of liver fibrosis. However, the change in the WFA ${ }^{+}-M 2 B P$ level after HCV eradication and its association with HCC development after the achievement of an SVR with IFN-free therapy remains uncertain. The aim of this study was thus to determine the impact of WFA ${ }^{+}$ M2BP on the prediction of HCC development after HCV eradication.

\section{Methods}

\section{Patients}

A total of 522 patients who achieved an SVR with anti-viral therapy between March 2004 and December 2019 were enrolled in this study. All participants met the following inclusion and exclusion criteria: (1) presence of persistent HCV infection; (2) negativity for hepatitis B surface antigen or human immunodeficiency virus; (3) negative history of other chronic liver diseases (autoimmune hepatitis, primary biliary cirrhosis, hemochromatosis, and Wilson's disease); (4) absence of HCC or any suspicious lesions detected on ultrasonography, dynamic computed tomography, or magnetic resonance imaging at enrollment; (5) negative history of previous treatment for HCC or liver transplantation; (6) followed-up period for $\geq 6$ months after the end of treatment (EOT); and (7) absence of HCC development within 6 months after the EOT.

This study's protocol was approved by the Juntendo University Shizuoka Hospital's Ethics Committee, and the study was performed in accordance with the 2013 revision of the Declaration of Helsinki.

\section{WFA-M2BP Measurement}

All routine laboratory data were collected immediately before treatment. The FIB-4 index was calculated as previously described [11]. Serum WFA+-M2BP levels were measured using pre-treatment serum samples stored at $-20^{\circ} \mathrm{C}$. WFA ${ }^{+}-M 2 B P$ quantification was performed usung a WFA-antibody immunoassay using a commercially available kit (HISCL M2BPGi; Sysmex Co., Kobe, Japan) and a fully automatic immunoanalyzer (HISCL-5000; Sysmex Co.). A SVR was defined as negativity for serum HCV RNA at SVR24.

\section{Patient Follow-up}

Serum tumor markers and ultrasonography were performed at least once every 6 months during the follow-up period. The negativity of serum HCV-RNA was confirmed annually. HCC diagnosis was 
confirmed predominantly via imaging studies, including dynamic computed tomography and magnetic resonance imaging. When typical imaging features were absent, a fine-needle aspiration biopsy was performed. The follow-up period was terminated on December 312019.

\section{Statistical Analyses}

Categorical data were compared using the corrected chi-squared method. Continuous variables were analyzed using the Mann-Whitney U test. Factors associated with HCC development were determined using Cox proportional hazard models, and the $\mathrm{HR}$ and $95 \% \mathrm{Cl}$ were calculated. The cumulative incidence of HCC development was determined by the Kaplan-Meier method, and differences were tested using the log-rank test. $P<0.05$ was considered statistically significant. All statistical analyses were performed using PASW Statistics 18 (IBM SPSS, Chicago, IL, USA).

\section{Results}

\section{Patient Characteristics}

A total of $522 \mathrm{HCV}$ patients who achieved an SVR were enrolled in this study; the clinical characteristics are summarized in Table 1. Between March 2004 and December 2019, 228 patients were treated with IFNbased therapy and 294 patients treated with IFN-free therapy. Among the 228 patients treated with IFNbased therapy, 172 were treated with pegylated-IFN plus ribavirin combination therapy for 24-72 weeks, while 56 were treated with pegylated IFN plus ribavirin combined with an NS3/4 protease inhibitor: 25 with telaprevir, 22 with simeprevir, 9 with faldaprevir. Among the 294 patients treated with IFN-free DAA therapy for 8-12 weeks: 53 were treated with daclatasvir/asunaprevir, 111 with ledipasvir/sofosbuvir, 99 with sofosbuvir/ribavirin, 10 with elbasvir/grazoprevir, 3 with ombitasvir/paritaprevir/ritonavir, and 18 with glecaprevir/pibrentasvir. 
Table 1

Patient characteristics according to treatment regimen

\begin{tabular}{|c|c|c|c|c|}
\hline Variables & $\begin{array}{l}\text { All } \\
n=522\end{array}$ & $\begin{array}{l}\text { IFN-based } \\
\text { therapy } \\
n=228\end{array}$ & $\begin{array}{l}\text { IFN-free therapy } \\
n=294\end{array}$ & P-value \\
\hline Age $\left(\right.$ years) ${ }^{\dagger}$ & $62(20-88)$ & $58(20-85)$ & $67(25-88)$ & $\begin{array}{l}< \\
0.001^{\ddagger}\end{array}$ \\
\hline Sex (male/female) & $278 / 244$ & 137 / 91 & $141 / 153$ & $0.004 \S$ \\
\hline Genotype 1/2 & $292 / 230$ & $111 / 117$ & $181 / 113$ & $0.002^{\S}$ \\
\hline HCV-RNA $(\log I \mathrm{IU} / \mathrm{L})^{\dagger}$ & $6.3(1.2-7.8)$ & $6.2(1.2-7.8)$ & $6.4(3.1-7.8)$ & $0.025^{\ddagger}$ \\
\hline \multicolumn{5}{|l|}{ At baseline } \\
\hline Albumin $(\mathrm{g} / \mathrm{dL})^{\dagger}$ & $4.2(2.9-5.2)$ & $4.2(3.3-4.8)$ & $4.2(2.9-5.2)$ & $0.690^{\ddagger}$ \\
\hline Total bilirubin $(\mathrm{mg} / \mathrm{dL})^{\dagger}$ & $0.7(0.3-2.9)$ & $0.7(0.3-2.1)$ & $0.7(0.3-2.9)$ & $0.257^{\ddagger}$ \\
\hline $\mathrm{AST}(\mathrm{IU} / \mathrm{L})^{+}$ & $39(10-499)$ & $42(13-499)$ & $36(10-281)$ & $0.005^{\ddagger}$ \\
\hline $\operatorname{ALT}(I U / L)^{+}$ & $42(9-1071)$ & $51(11-1071)$ & $35(9-366)$ & $\begin{array}{l}< \\
0.001^{\ddagger}\end{array}$ \\
\hline $\begin{array}{l}\text { Platelet counts }\left(\times 10^{4} / \mu \mathrm{L}\right) \\
+\end{array}$ & $16.9(0.5-38.3)$ & $17.6(4.3-38.3)$ & $16.1(0.5-36.7)$ & $0.019^{\ddagger}$ \\
\hline $\operatorname{AFP}(\mathrm{ng} / \mathrm{mL})^{+}$ & $4(1-459)$ & $5(1-358)$ & $4(1-459)$ & $0.004^{\ddagger}$ \\
\hline FIB-4 index ${ }^{\dagger}$ & $\begin{array}{l}2.46(0.30- \\
33.42)\end{array}$ & $\begin{array}{l}2.24(0.31- \\
16.22)\end{array}$ & $2.68(0.30-33.42)$ & $\begin{array}{l}< \\
0.001^{\ddagger}\end{array}$ \\
\hline $\mathrm{WFA}^{+}-\mathrm{M} 2 \mathrm{BP}(\mathrm{COI})^{+}$ & $\begin{array}{l}1.64(0.20- \\
19.81)\end{array}$ & $\begin{array}{l}1.63(0.24- \\
18.11)\end{array}$ & $1.65(0.20-19.81)$ & $0.948^{\ddagger}$ \\
\hline \multicolumn{5}{|l|}{ At SVR24 } \\
\hline Albumin $(\mathrm{g} / \mathrm{dL})^{\dagger}$ & $4.3(3.2-6.6)$ & $4.3(3.2-5.5)$ & $4.3(3.2-6.6)$ & $0.376^{\ddagger}$ \\
\hline $\operatorname{AST}(\mathrm{IU} / \mathrm{L})^{\dagger}$ & $22(4-111)$ & $21(11-111)$ & $23(4-110)$ & $0.404^{\ddagger}$ \\
\hline $\operatorname{ALT}(I U / L)^{\dagger}$ & $16(2-146)$ & $17(5-146)$ & $15(2-95)$ & $0.027^{\ddagger}$ \\
\hline
\end{tabular}

†Data are expressed as the median (range), $¥$ Mann-Whitney U-test, §Chi-squared test. AFP, alphafetoprotein; ALT alanine aminotransferase; AST, aspartate aminotransferase, COI, cut off index; FIB-4, fibrosis-4; HCV, hepatitis C virus; IFN, interferon; SVR, sustained virologic response; WFA ${ }^{+}-M 2 B P$, Wisteria floribunda agglutinin-positive Mac-2-binding protein. 


\begin{tabular}{|c|c|c|c|c|}
\hline Variables & $\begin{array}{l}\text { All } \\
n=522\end{array}$ & $\begin{array}{l}\text { IFN-based } \\
\text { therapy } \\
n=228\end{array}$ & $\begin{array}{l}\text { IFN-free therapy } \\
n=294\end{array}$ & P-value \\
\hline $\begin{array}{l}\text { Platelet counts }\left(\times 10^{4} / \mu \mathrm{L}\right) \\
+\end{array}$ & $17.3(0.2-42.5)$ & $17.3(5.5-39.0)$ & $17.3(0.2-42.5)$ & $0.592^{\ddagger}$ \\
\hline $\operatorname{AFP}(\mathrm{ng} / \mathrm{mL})^{\dagger}$ & $3(1-27)$ & $3(1-27)$ & $3(1-17)$ & $0.095^{\ddagger}$ \\
\hline FIB-4 index ${ }^{\dagger}$ & $\begin{array}{l}2.10(0.3- \\
111.86)\end{array}$ & $1.81(0.33-7.97)$ & $\begin{array}{l}2.26(0.38- \\
111.86)\end{array}$ & $\begin{array}{l}< \\
0.001^{\ddagger}\end{array}$ \\
\hline $\mathrm{WFA}^{+}-\mathrm{M} 2 \mathrm{BP}(\mathrm{COI})^{\dagger}$ & $\begin{array}{l}0.89(0.13- \\
16.65)\end{array}$ & $0.81(0.13-7.08)$ & $0.96(0.17-16.65)$ & $0.004^{\ddagger}$ \\
\hline \multicolumn{5}{|c|}{$\begin{array}{l}\text { TData are expressed as the median (range), } ¥ \text { Mann-Whitney U-test, §Chi-squared test. AFP, alpha- } \\
\text { fetoprotein; ALT alanine aminotransferase; AST, aspartate aminotransferase, COI, cut off index; FIB-4, } \\
\text { fibrosis-4; HCV, hepatitis C virus; IFN, interferon; SVR, sustained virologic response; WFA -M2BP, } \\
\text { Wisteria floribunda agglutinin-positive Mac-2-binding protein. }\end{array}$} \\
\hline
\end{tabular}

There was a greater number of patients with HCV genotype 1 infection, females and elderly patients, and the serum aspartate aminotransferase (AST) level, alanine aminotransferase (ALT) level and platelet counts were lower in the IFN-free therapy group than in the IFN-based therapy group. The WFA ${ }^{+}-\mathrm{M} 2 \mathrm{BP}$ levels did not differ between the two groups at baseline and significantly decreased at SVR week 24 (SVR24) in both groups compared to baseline $(P<0.001)$. The albumin and platelet counts were significantly increased at SVR24, while the AST, ALT, and alpha-fetoprotein (AFP) levels were significantly decreased at SVR24 compared to baseline $(P<0.001)$.

\section{HCC Development After Achievement Of An SVR}

Among the 522 patients, 14 (3.4\%) developed HCC during a median follow-up period of 2.9 years (range, 0.5-13.4 years). The estimated cumulative incidences of HCC development were $1.7 \%$ and $3.3 \%$ at 3 and 5 years, respectively (Fig. 1). Further, the cumulative incidence of HCC development did not significantly differ according to the treatment regimen (Fig. 2). The albumin levels $(P=0.004)$, and platelet counts $(P=$ $0.002)$ were significantly lower and the AFP levels $(P=0.034), F I B-4$ index $(P=0.003)$, WFA $A^{+}-M 2 B P$ level at baseline $(P=0.002)$, and WFA $A^{+}-M 2 B P$ level at SVR24 $(P<0.001)$ were significantly higher in those who developed HCC than in those who did not (Table 2). 
Table 2

Patient characteristics according to hepatocellular carcinoma development

\begin{tabular}{|c|c|c|c|}
\hline \multirow[t]{2}{*}{ Variables } & $\mathrm{HCC}$ & No-HCC & P-value \\
\hline & $n=14$ & $\mathrm{n}=508$ & \\
\hline Age $\left(\right.$ years) ${ }^{\dagger}$ & $72(45-82)$ & $62(20-88)$ & $0.056^{\ddagger}$ \\
\hline Sex (male/female) & $10 / 4$ & $268 / 240$ & $0.133 \S$ \\
\hline Genotype 1/2 & $11 / 3$ & $281 / 227$ & $0.070 \S$ \\
\hline HCV-RNA $(\log I \mathrm{I} / \mathrm{L})^{\dagger}$ & $6.3(1.6-7.8)$ & $6.4(1.2-7.1)$ & $0.937^{\ddagger}$ \\
\hline \multicolumn{4}{|l|}{ At baseline } \\
\hline Albumin $(\mathrm{g} / \mathrm{dL})^{\dagger}$ & $3.9(3.4-4.7)$ & $4.2(2.9-5.2)$ & $0.004^{\ddagger}$ \\
\hline Total bilirubin $(\mathrm{mg} / \mathrm{dL})^{\dagger}$ & $0.8(0.5-1.6)$ & $0.7(0.3-2.9)$ & $0.060^{\ddagger}$ \\
\hline $\operatorname{AST}(\mathrm{IU} / \mathrm{L})^{+}$ & $46(22-195)$ & $39(10-499)$ & $0.238^{\ddagger}$ \\
\hline $\operatorname{ALT}(\mathrm{IU} / \mathrm{L})^{\dagger}$ & $49(15-209)$ & $42(9-1071)$ & $0.427^{\ddagger}$ \\
\hline Platelet counts $\left(\times 10^{4} / \mu \mathrm{L}\right)^{\dagger}$ & $11.6(6.1-20.2)$ & $17.0(0.5-38.3)$ & $0.002^{\ddagger}$ \\
\hline $\operatorname{AFP}(\mathrm{ng} / \mathrm{mL})^{+}$ & $7(1-142)$ & $4(1-459)$ & $0.034^{\ddagger}$ \\
\hline FIB-4 index ${ }^{\dagger}$ & $3.99(1.69-16.22)$ & $2.41(0.30-33.42)$ & $0.003^{\ddagger}$ \\
\hline $\mathrm{WFA}^{+}-\mathrm{M} 2 \mathrm{BP}(\mathrm{COI})^{\dagger}$ & $3.72(0.88-15.87)$ & $1.62(0.20-19.81)$ & $0.002^{\ddagger}$ \\
\hline \multicolumn{4}{|l|}{ At SVR24 } \\
\hline Albumin $(g / d L)^{\dagger}$ & $4.3(3.2-4.7)$ & $4.3(3.4-6.6)$ & $0.280^{\ddagger}$ \\
\hline $\operatorname{AST}(I U / L)^{\dagger}$ & $27(14-53)$ & $22(4-111)$ & $0.056^{\ddagger}$ \\
\hline $\operatorname{ALT}(\mathrm{IU} / \mathrm{L})^{\dagger}$ & $20(11-52)$ & $16(2-146)$ & $0.029^{\ddagger}$ \\
\hline Platelet counts $\left(\times 10^{4} / \mu \mathrm{L}\right)^{\dagger}$ & $14.0(3.4-19.0)$ & $17.4(0.2-42.5)$ & $0.005^{\ddagger}$ \\
\hline $\operatorname{AFP}(n g / m L)^{\dagger}$ & $4(1-15)$ & $3(1-27)$ & $0.106^{\ddagger}$ \\
\hline FIB-4 index ${ }^{+}$ & $2.88(1.46-9.66)$ & $2.07(0.33-111.86)$ & $0.005^{\ddagger}$ \\
\hline
\end{tabular}

†Data are expressed as median (range), $¥$ Mann-Whitney U-test, §̧Chi-squared test. AFP, alphafetoprotein; ALT alanine aminotransferase; AST, aspartate aminotransferase; COI, cut off index; FIB-4, fibrosis-4; HCC, hepatocellular carcinoma; HCV, hepatitis C virus; SVR, sustained virologic response; WFA+-M2BP, Wisteria floribunda agglutinin-positive Mac-2-binding protein. 


\begin{tabular}{|llll|}
\hline Variables & $\begin{array}{l}\text { HCC } \\
\mathbf{n = 1 4}\end{array}$ & $\begin{array}{l}\text { No-HCC } \\
\mathbf{n = 5 0 8}\end{array}$ & P-value \\
\hline WFA ${ }^{+}-\mathrm{M} 2 \mathrm{BP}(\mathrm{COI})^{+}$ & $1.73(0.52-5.90)$ & $0.88(0.13-16.65)$ & $<0.001^{\ddagger}$ \\
\hline $\begin{array}{l}\text { tData are expressed as median (range), } \neq \text { Mann-Whitney U-test, } \S \text { Chi-squared test. AFP, alpha- } \\
\text { fetoprotein; ALT alanine aminotransferase; AST, aspartate aminotransferase; COI, cut off index; FIB-4, } \\
\text { fibrosis-4; HCC, hepatocellular carcinoma; HCV, hepatitis C Virus; SVR, sustained virologic response; } \\
\text { WFA+-M2BP, Wisteria floribunda agglutinin-positive Mac-2-binding protein. }\end{array}$ \\
\hline
\end{tabular}

\section{Risk Analysis}

To identify non-invasive markers predicting HCC development in patients achieving an SVR, a Cox proportional hazard analysis was performed (Table 3). Univariate analysis revealed that male sex, serum albumin level, total bilirubin level, platelet count, FIB-4 index, and the WFA ${ }^{+}-M 2 B P$ level at baseline and SVR24 were associated with HCC development. Multivariate analysis identified three independent risk factors: age (hazard ratio $[H R]=1.073,95 \%$ confidence interval $[\mathrm{Cl}] 1.016-1.133, \mathrm{P}=0.011$ ), platelet counts $(H R=0.876,95 \% \mathrm{Cl} 0.773-0.992, \mathrm{P}=0.036)$, and WFA ${ }^{+}-\mathrm{M} 2 \mathrm{BP}$ level at SVR24 $(\mathrm{HR}=1.215,95 \% \mathrm{Cl}$ $1.031-1.432, \mathrm{P}=0.020)$. 
Table 3

Factors associated with hepatocellular carcinoma development after achievement of a sustained virologic response

\begin{tabular}{|c|c|c|c|c|}
\hline \multirow[t]{2}{*}{ Variables } & \multicolumn{2}{|l|}{ Univariate analysis } & \multicolumn{2}{|l|}{ Multivariate analysis } \\
\hline & $\mathrm{HR}(95 \% \mathrm{Cl})$ & $P$ value & $\mathrm{HR}(95 \% \mathrm{Cl})$ & $P$ value \\
\hline Age every 1 year & $1.069(1.014-1.127)$ & 0.211 & $1.073(1.016-1.133)$ & 0.012 \\
\hline Sex female vs. male & $0.476(0.149-1.521)$ & 0.002 & & \\
\hline IFN-based / IFN-free therapy & $1.682(0.417-6.784)$ & 0.465 & & \\
\hline HCV genotype 2 vs. 1 & $0.330(0.092-1.185)$ & 0.089 & & \\
\hline HCV-RNA every 1.0 loglU/mL & $0.961(0.622-1.487)$ & 0.860 & & \\
\hline \multicolumn{5}{|l|}{ At baseline } \\
\hline Albumin every $1 \mathrm{~g} / \mathrm{dL}$ & $0.159(0.040-0.634)$ & 0.009 & & \\
\hline Total bilirubin every $1 \mathrm{mg} / \mathrm{dL}$ & $3.075(1.030-9.178)$ & 0.044 & & \\
\hline AST every $1 \mathrm{IU} / \mathrm{L}$ & $1.004(0.997-1.011)$ & 0.246 & & \\
\hline ALT every $1 \mathrm{IU} / \mathrm{L}$ & $1.000(0.994-1.006)$ & 0.970 & & \\
\hline Platelet counts every $1 \times 10^{4} / \mu \mathrm{L}$ & $0.854(0.771-0.946)$ & 0.002 & $0.876(0.774-0.992)$ & 0.037 \\
\hline AFP every $1 \mathrm{ng} / \mathrm{mL}$ & $1.005(0.998-1.013)$ & 0.164 & & \\
\hline FIB-4 index every 1.00 & $1.140(1.059-1.228)$ & 0.001 & & \\
\hline WFA+-M2BP every 1 COI & $1.200(1.093-1.317)$ & $<0.001$ & & \\
\hline \multicolumn{5}{|l|}{ At SVR24 } \\
\hline Albumin every $1 \mathrm{~g} / \mathrm{dL}$ & $0.143(0.032-0.642)$ & 0.011 & & \\
\hline AST every $1 \mathrm{IU} / \mathrm{L}$ & $1.019(0.992-1.047)$ & 0.164 & & \\
\hline ALT every $1 \mathrm{IU} / \mathrm{L}$ & $1.011(0.988-1.034)$ & 0.366 & & \\
\hline Platelet counts every $1 \times 10^{4} / \mu \mathrm{L}$ & $0.855(0.772-0.948)$ & 0.003 & & \\
\hline AFP every 1 ng/mL & $1.138(0.984-1.316)$ & 0.081 & & \\
\hline FIB-4 index every 1.00 & $1.023(0.982-1.065)$ & 0.270 & & \\
\hline WFA+-M2BP every $1 \mathrm{COI}$ & $1.305(1.140-1.494)$ & 0.001 & $1.215(1.031-1.432)$ & 0.020 \\
\hline \multicolumn{5}{|c|}{$\begin{array}{l}\text { AFP, alpha-fetoprotein; ALT alanine aminotransferase; } \mathrm{AST} \text {, aspartate aminotransferase; } \mathrm{Cl} \text {, confidence } \\
\text { interval; COI, cut off index; FIB-4, fibrosis-4; HCV, hepatitis C virus; HR, hazard ratio; IFN, interferon; } \\
\text { SVR, sustained virologic response; WFA+-M2BP, Wisteria floribunda agglutinin-positive Mac-2-binding } \\
\text { protein. }\end{array}$} \\
\hline
\end{tabular}


Analysis of the area under receiver operator characteristics curve (AUROC) revealed that the WFA ${ }^{+}-M 2 B P$ level at SVR24 was more predictive of HCC development than the WFA ${ }^{+}-M 2 B P$ level at baseline (AUROC = 0.805 and 0.744 , respectively, Fig. 3). Furthermore, receiver operator characteristics curve analysis indicated that an WFA+-M2BP level at SVR24 of $\geq 1.62$ cut off index (COI) was the cut-off value for the prediction of HCC development (adjusted HR $=12.565,95 \% \mathrm{Cl} 3.501-45.092, \mathrm{P}<0.001$ ). The 3 - and 5year cumulative incidence rates of HCC development in patients with an WFA ${ }^{+}$-M2BP level of $<1.62 \mathrm{COI}$ were $1 \%$ and $1.6 \%$, respectively, whereas those of patients with an WFA ${ }^{+}-M 2 B P$ level of $\geq 1.62 \mathrm{COI}$ were $4.7 \%$ and $12.5 \%$, respectively $(P<0.001$, Fig. 4$)$.

Among patients treated with IFN-based therapy, the 3- and 5-year cumulative incidences of HCC development in patients with a WFA ${ }^{+}-\mathrm{M} 2 \mathrm{BP}$ level of $<1.62 \mathrm{CO}$ were $0.6 \%$ and $1.3 \%$, respectively, whereas those of patients with a WFA ${ }^{+}$-M2BP level of $\geq 1.62$ COI were $3.1 \%$ and $12.6 \%$, respectively $(P<0.001$, Fig. 5a). Among patients treated with IFN-free therapy, the 3-year cumulative incidence of HCC development was $1.4 \%$ in patients with a WFA ${ }^{+}-\mathrm{M} 2 \mathrm{BP}$ of $<1.62 \mathrm{COI}$, and $5.8 \%$ in patients with a WFA ${ }^{+}$ M2BP level of $\geq 1.62 \mathrm{COI}(P=0.042$, Fig. $5 b)$.

\section{Discussion}

The present study aimed to determine the utility of the post-treatment WFA+-M2BP level in the prediction of HCC development after HCV eradication. Our findings revealed that age, platelet counts, and the WFA ${ }^{+}$ M2BP level at SVR24 were useful predictors of HCC development after HCV eradication, regardless of the treatment regimen. Among these factors, both the platelet count and WFA ${ }^{+}-M 2 B P$ level were previously found to be significantly associated with the severity of histological liver fibrosis [10,12]. In addition, age is a well-known surrogate marker of disease duration and is associated with more advanced fibrosis [13]. Several previous studies also showed that old age and advanced liver fibrosis were significant risk factors for HCC development $[4,6,14,15]$. Based on these results, the European Association for the Study of the Liver (EASL) recommends that patients with advanced fibrosis and cirrhosis who achieve an SVR should undergo surveillance for HCC every 6 months [16]. Our findings confirmed the clinical importance of assessing the severity of liver fibrosis in the development of HCC after HCV eradication. Although liver biopsy has been recognized as the gold standard for the assessment of fibrosis, it can exhibit sampling variability and risk of lethal complications such as liver bleeding. Therefore, noninvasive markers such as the WFA ${ }^{+}-M 2 B P$ level are important and useful for assessing the severity of liver fibrosis. We previously reported that the pre-treatment WFA ${ }^{+}-M 2 B P$ level was a useful predictor of $\mathrm{HCC}$ development in patients who achieved an SVR by IFN-based therapy [9]. However, the present study demonstrated that WFA ${ }^{+}$M2BP level at SVR24 was more useful in predicting HCC development than pre-treatment WFA ${ }^{+}$-M2BP level. In our previous report, we showed that the WFA ${ }^{+}$-M2BP level is affected by necroinflammatory activity in the liver [9]. In this study, the WFA ${ }^{+}-M 2 B P$ levels significantly decreased after HCV eradication. These results suggest that the WFA ${ }^{+}-\mathrm{M} 2 \mathrm{BP}$ level at SVR24 is more useful than the pre-treatment level for assessing liver fibrosis and predicting HCC development.

Page $11 / 19$ 
Another finding of the present study was that the incidence of HCC development after HCV eradication was comparable between IFN-based therapy and IFN-free therapy. Initially, some studies reported that the incidence of HCC development after HCV eradication was unexpectedly high despite the lack of long-term follow-up $[17,18]$. However, several recent studies have revealed that the incidence of HCC development did not significantly differ between IFN-based therapy and IFN-free therapy, and this phenomenon can be explained by patient characteristics such as age and liver function $[19,20]$.

In our study, there were more elderly patients, females, patients with HCV genotype 1 infection, and patients with low platelet count, who were considered to be resistant to previous IFN-based therapy, in the IFN-free therapy group relative to the IFN-based therapy group.

The present study has several limitations. First, the incidence of HCC development was low (9 of 228 patients treated with IFN-based therapy and 5 of 294 patients treated with IFN-free therapy) because our study was retrospectively performed in a single center. Second, the observation period was relatively short in patients treated with IFN-free therapy; the median observation period was only 3 years in the IFN-free therapy group, compared to 5.3 years in the IFN-based therapy group. Third, the patient background characteristics that might affect HCC development differed between patients treated with IFN-based therapy and IFN-free therapy. Therefore, a large-scale prospective study is required to validate our study findings.

In summary, the incidence of HCC after HCV eradication is comparable between IFN-based therapy and IFN-free therapy. The WFA'-M2BP level at SVR24 is a useful predictor of HCC development after HCV eradication, regardless of the treatment regimen. Our results suggested that it was important to assess liver fibrosis using the WFA ${ }^{+}$-M2BP level at SVR24 for prediction of HCC development after achieving an SVR.

\section{Abbreviations}

AFP, Alpha-fetoprotein; ALT, Alanine aminotransferase; AST, Aspartate aminotransferase; $\mathrm{Cl}$, Confidence interval; COI, Cut off index; EOT, End of treatment; FIB-4, Fibrosis-4; HCV, Hepatitis C virus; HCC, Hepatocellular carcinoma; HR, Hazard ratio; IFN, Interferon; SVR, Sustained virological response; SVR24, Sustained virological response week 24; WFA+-M2BP, Wisteria floribunda agglutinin-positive Mac-2binding protein

\section{Declarations}

\section{Acknowledgments}

Not applicable.

\section{Funding}

This research received no external funding. 


\section{Conflicts of Interest}

TG received honoraria from AbbVie, Gilead Sciences Inc., and MSD K.K. and research funding from AbbVie, Otsuka Pharmaceutical, Mitsubishi Tanabe Pharma, JIMRO Co Ltd, and Takeda Pharmaceutical

\section{Ethics approval and consent to participate}

This study protocol was approved by the Juntendo University Shizuoka Hospital's Ethics Committee, and performed in accordance with the 2013 revision of the Helsinki Declaration.

\section{Consent for publication}

Consent was obtained from all subjects for publication of this case report.

\section{Availability of data and materials}

The data supporting the conclusions of this article are included within the article.

\section{Authors contributions}

SS and TG drafted the manuscript; SS, HT, YK, DK, SS, NA, NY, AM, YS and TG followed up the patients and collected clinical data. All authors read and approved the manuscript.

\section{References}

1. World Health Organization. Hepatitis C fact Sheet World Health Organization 2017. Available at: [https://www.who.int/en/news-room/fact-sheets/detail/hepatitis-c]. Accessed [September 7, 2020].

2. Tanaka J, Akita T, Ko K, Miura Y, Satake M. Epidemiological Research Group on Viral Hepatitis and its Long-term Course, Ministry of Health, Labour and Welfare of Japan. Countermeasures against viral hepatitis B and C in Japan: An epidemiological point of view. Hepatol Res 2019, 49, 990-1002.

3. Morgan RL, Baack B, Smith BD, Yartel A, Pitasi M, Falck-Ytter Y. Eradication of hepatitis C virus infection and the development of hepatocellular carcinoma: A meta-analysis of observational studies. Ann Intern Med 2013, 158, 329-337.

4. Nahon $P$, Bourcier $V$, Layese $R$, et al. Eradication of hepatitis $C$ virus infection in patients with cirrhosis reduces risk of liver and non-liver complications. Gastroenterology 2017, 152, 142-156.e2.

5. Backus LI, Boothroyd DB, Phillips BR, Belperio P, Halloran J, Mole LA. A sustained virologic response reduces risk of all-cause mortality in patients with hepatitis C. Clin Gastroenterol Hepatol 2011, 9(6), 509-516.e1.

6. van der Meer AJ, Veldt BJ, Feld JJ, et al. Association between sustained virological response and allcause mortality among patients with chronic hepatitis $C$ and advanced hepatic fibrosis. JAMA 2012, $308,2584-2593$. 
7. Cardoso AC, Moucari R, Figueiredo-Mendes C, et al. Impact of peginterferon and ribavirin therapy on hepatocellular carcinoma: incidence and survival in hepatitis $C$ patients with advanced fibrosis. $J$ Hepatol 2010, 52, 652-657.

8. Murata A, Genda T, Ichida T, et al. Pretreatment AKR1B10 expression predicts the risk of hepatocellular carcinoma development after hepatitis C virus eradication. World J Gastroenterol 2016, 22, 7569-78.

9. Sato S, Genda T, Ichida T, et al. Prediction of hepatocellular carcinoma development after hepatitis C virus eradication using serum Wisteria floribunda agglutinin-positive Mac-2-binding protein. Int $\mathrm{J}$ Mol Sci 2016, 17, 2143.

10. Toshima T, Shirabe K, Ikegami T, et al. A novel serum marker, glycosylated Wisteria floribunda agglutinin-positive Mac-2 binding protein (WFA(+)-M2BP), for assessing liver fibrosis. J Gastroenterol 2015, 50, 76-84.

11. Vallet-Pichard A, Mallet V, Nalpas B, et al. FIB-4: An inexpensive and accurate marker of fibrosis in HCV infection. comparison with liver biopsy and fibrotest. Hepatology 2007, 46, 32-36.

12. Pohl A, Behling C, Oliver D, Kilani M, Monson P, Hassanein T. Serum aminotransferase levels and platelet counts as predictors of degree of fibrosis in chronic hepatitis $\mathrm{C}$ virus infection. Am J Gastroenterol 2001, 96, 3142-3146.

13. Sterling RK, Stravitz RT, Luketic VA, et al. A comparison of the spectrum of chronic hepatitis C virus between Caucasians and African Americans. Clin Gastroenterol Hepatol 2004, 2, 469-473.

14. El-Serag HB, Kanwal F, Richardson P, Kramer J. Risk of hepatocellular carcinoma after sustained virological response in Veterans with hepatitis C virus infection. Hepatology 2016, 64, 130-137.

15. Kanwal F, Kramer JR, Asch SM, Cao Y, Li L, El-Serag HB. Long-term risk of hepatocellular carcinoma in HCV patients treated with direct acting antiviral agents. Hepatology 2020, 71, 44-55.

16. European Association for the Study of the Liver. EASL recommendations on treatment of hepatitis $C$ 2018. J Hepatol 2018, 69(2), 461-511.

17. Kozbial K, Moser S, Schwarzer R, et al. Unexpected high incidence of hepatocellular carcinoma in cirrhotic patients with sustained virologic response following interferon-free direct-acting antiviral treatment. J Hepatol 2016, 65, 856-858.

18. Conti F, Buonfiglioli F, Scuteri A, et al. Early occurrence and recurrence of hepatocellular carcinoma in HCV-related cirrhosis treated with direct-acting antivirals. J Hepatol 2016, 65, 727-733.

19. Nahon $P$, Layese R, Bourcier $V$, et al. Incidence of hepatocellular carcinoma after direct antiviral therapy for HCV in patients with cirrhosis included in surveillance programs. Gastroenterology 2018, 155, 1436-1450.e6.

20. Waziry R, Hajarizadeh B, Grebely J, et al. Hepatocellular carcinoma risk following direct-acting antiviral HCV therapy: A systematic review, meta-analyses, and meta-regression. J Hepatol 2017, 67, 1204-1212.

\section{Figures}




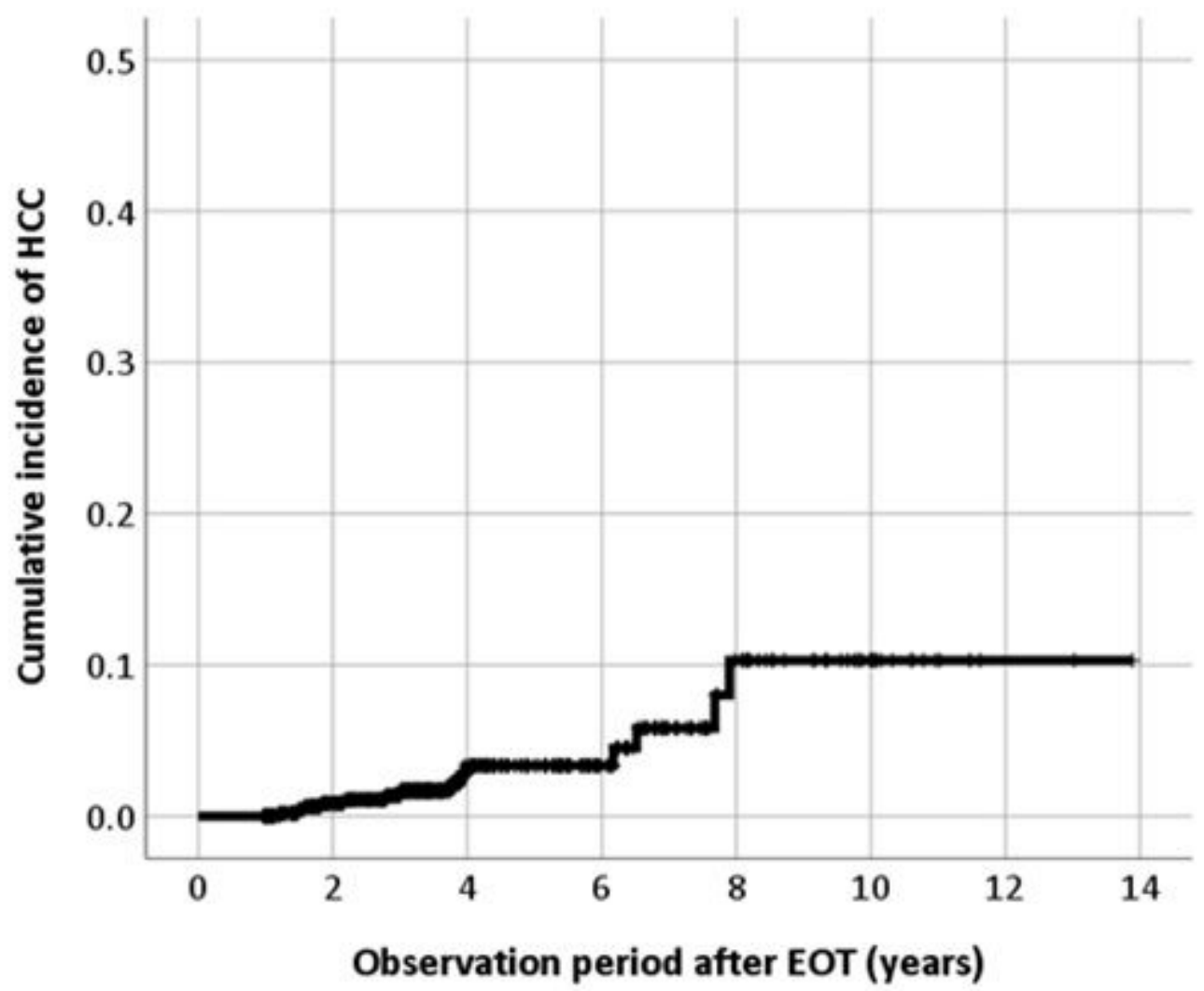

At risk

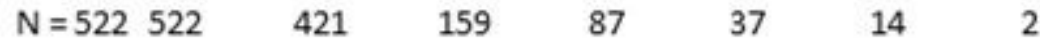

Figure 1

Cumulative incidence of hepatocellular carcinoma after end-of-treatment in all patients. EOT, end-oftreatment; HCC, hepatocellular carcinoma 


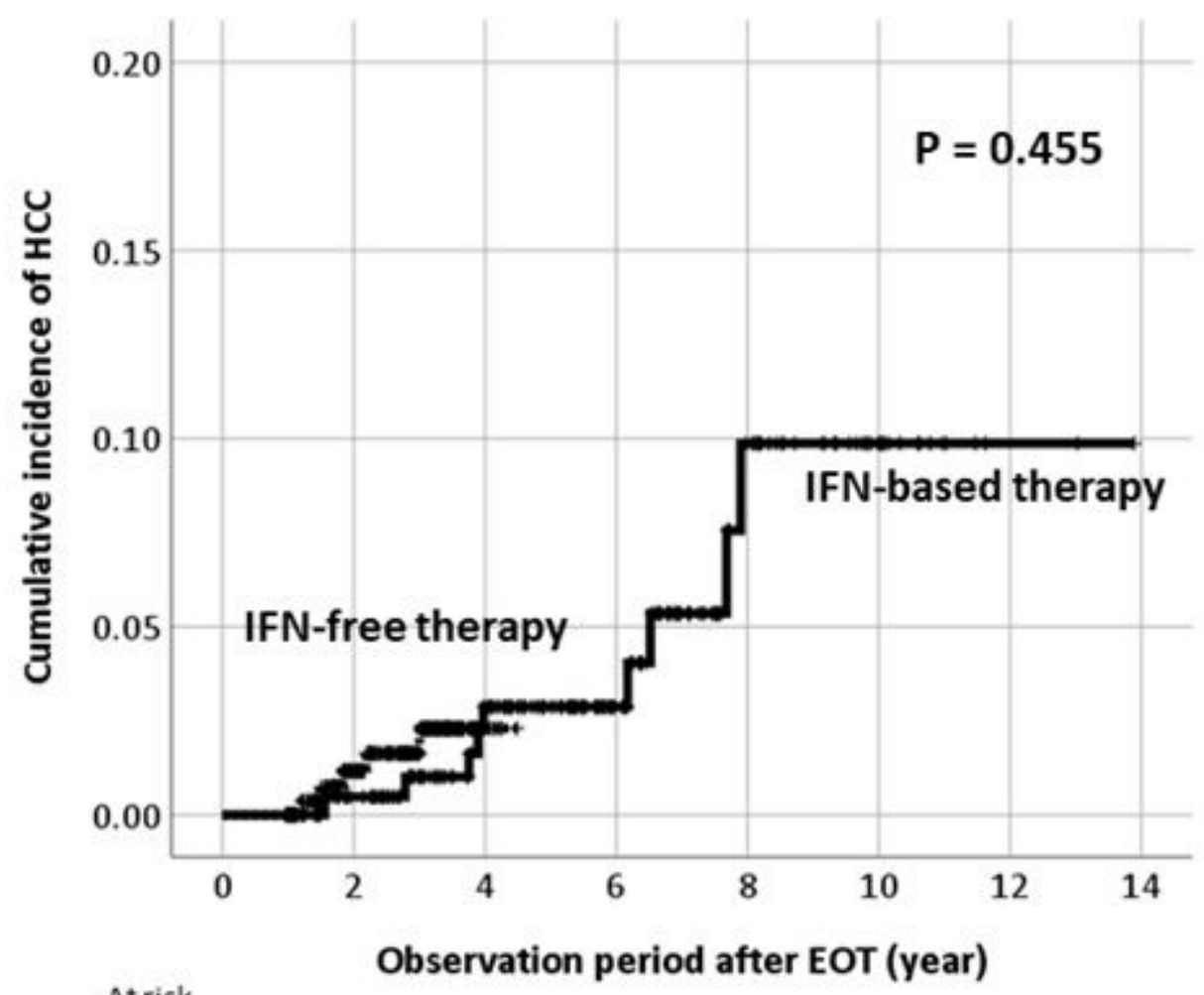

At risk

$\begin{array}{lllllll}\text { IFN } 228 & 199 & 153 & 87 & 37 & 14 & 1\end{array}$

$\begin{array}{lllllll}\text { Free } 294 & 221 & 5 & 0 & 0 & 0 & 0\end{array}$

Figure 2

Cumulative incidence of hepatocellular carcinoma according to treatment regimen. EOT, end-of-treatment; HCC, hepatocellular carcinoma 


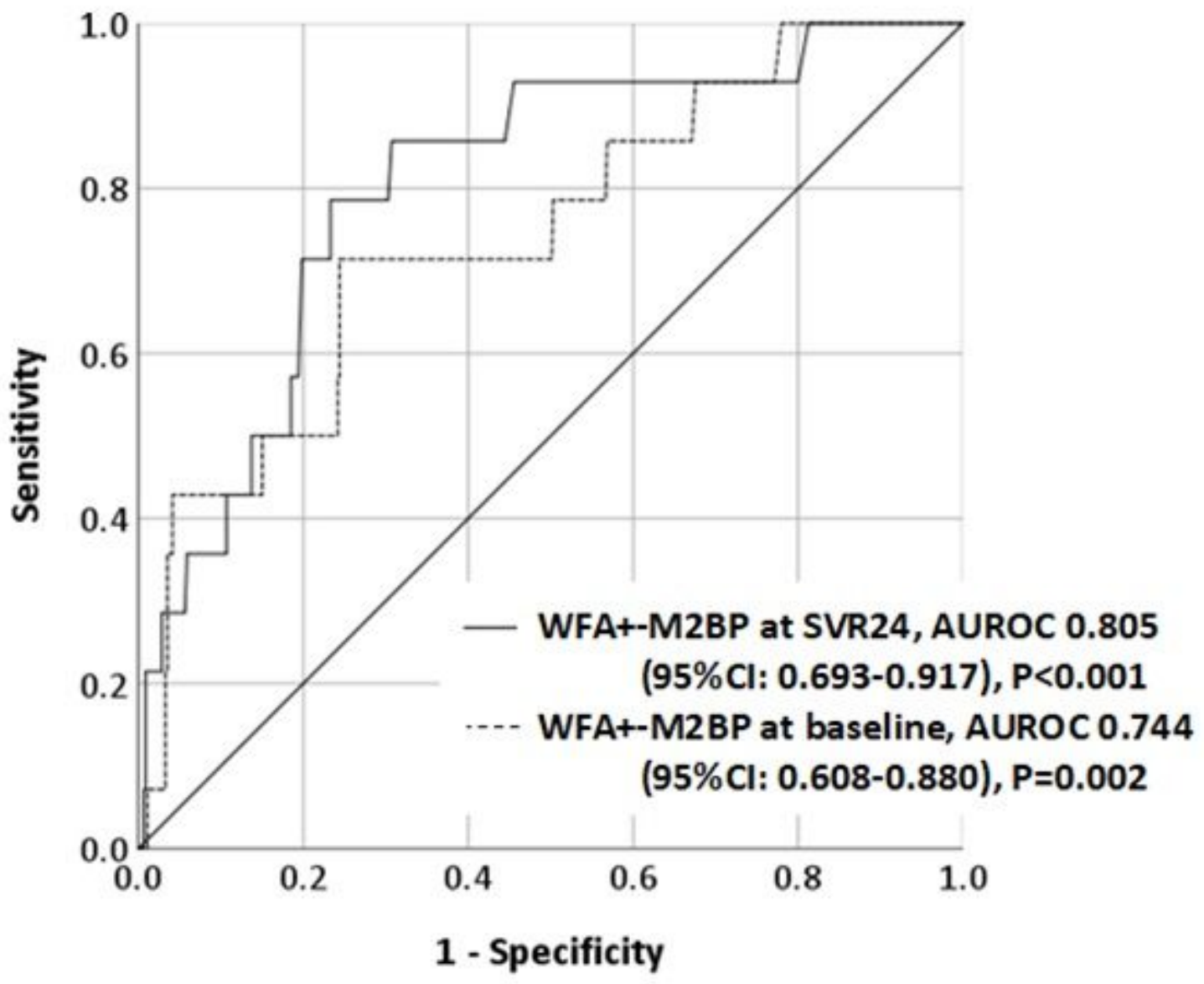

Figure 3

Receiver operating characteristic curve for the prediction of hepatocellular carcinoma development. SVR24, sustained virologic response at week 24; WFA+-M2BP, Wisteria floribunda agglutinin-positive Mac2-binding protein; AUC, area under the curve; $\mathrm{Cl}$, confidence interval 


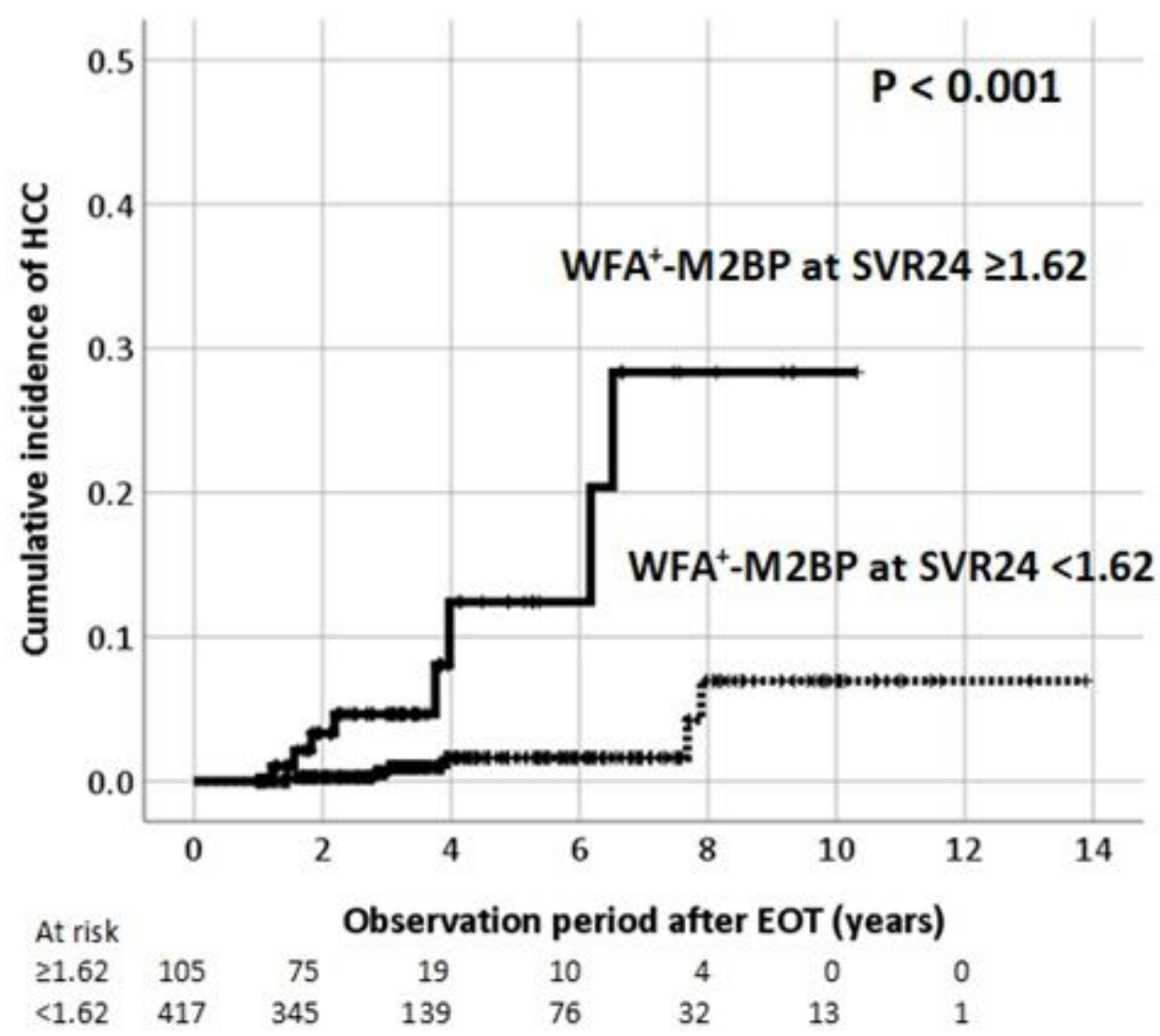

Figure 4

Cumulative incidence of hepatocellular carcinoma according to the Wisteria floribunda agglutinin-positive Mac-2-binding protein at sustained virologic response week 24. HCC, hepatocellular carcinoma; EOT, endof-treatment; SVR24, sustained virologic response at week 24; WFA+-M2BP, Wisteria floribunda agglutininpositive Mac-2-binding protein 
(a)

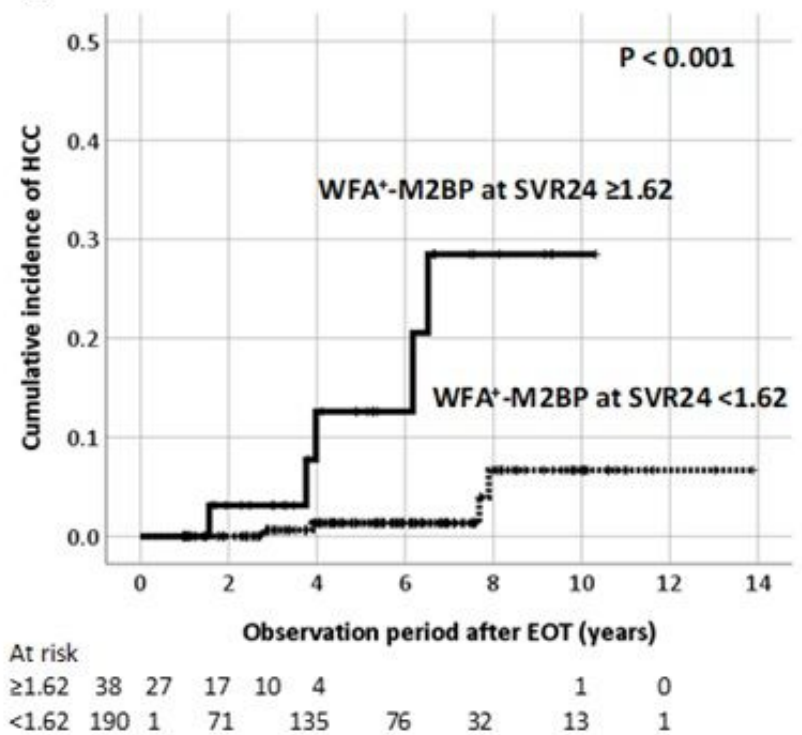

(b)

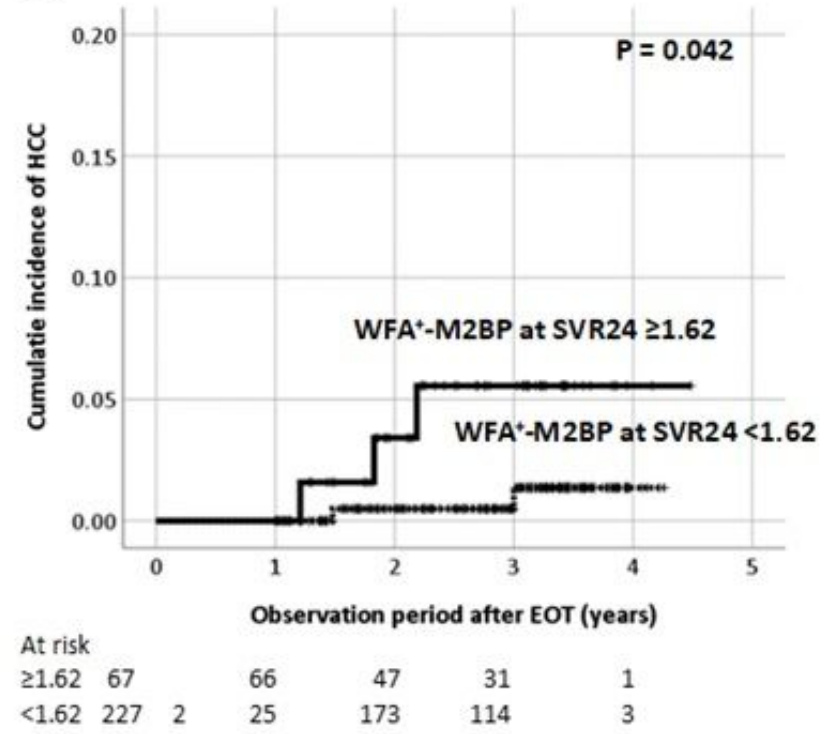

\section{Figure 5}

Cumulative incidence of hepatocellular carcinoma according to the Wisteria floribunda agglutinin-positive Mac-2-binding protein at sustained virologic response week 24 in patients treated with interferon-based therapy (a) and interferon-free therapy (b). EOT, end-of-treatment; HCC, hepatocellular carcinoma; SVR24, sustained virologic response at week 24; WFA+-M2BP, Wisteria floribunda agglutinin-positive Mac-2binding protein 